\title{
Renascimento e Novo Mundo: ensaio sobre a recepção das ideias renascentistas na cidade do Rio de Janeiro
}

Renaissance and New World: essay on reception of Renaissance ideas in the city of Rio de Janeiro.

\section{Antônio Edmilson Martins Rodrigues"}

Resumo: O presente artigo apresenta aos leitores algumas reflexões sobre as cidades na Renascença. Sobretudo, me interessa pensar as possíveis relações entre a concepção de cidade no Renascimento, suas formas, seus princípios e modos de agir, suas ambições de cultivo da vida ativa, e a cidade do Rio de Janeiro, considerada aqui uma cidade Renascentista nos Trópicos. A hipótese desenvolvida é de que a cidade do Rio de Janeiro é uma cidade clássica, e não uma feitoria, puro resultado do processo de desenvolvimento do mercantilismo europeu, em especial, o ibérico. Combinando, em especial, a ideia de utopia e a ideia de República, o Rio de Janeiro se torna o campo privilegiado de combinação de ideias e experiências.

Palavras chave: Novo Mundo, Cidades Renascentistas, Rio de Janeiro.

Abstract: The present article introduces to the readers some reflections on the cities in the Renaissance. Mainly interests me, to think of the possible relations between the conception of city in Renaissance, its forms, its principles and ways of acting, its growing ambitions of active life, and the city of Rio de Janeiro, is considered here as a Renaissance city in the Tropics. The hypothesis developed is that the city of Rio de Janeiro is a classic city, and not a trading post, pure result of the development process of European mercantilism, especially, the Iberian. Combining, especially, the idea of utopia and the idea of the

\footnotetext{
" Professor do Departamento de História Social da Cultura da PUC-Rio, e do Departamento de História da UERJ.
} 
Republic, Rio de Janeiro becomes the privileged field for the combination of ideas and experiences.

Keywords: New World, Renaissance cities, Rio de Janeiro.

O que será lido, a seguir, tem como base uma constatação. Qual seja: chama atenção dos estudiosos a potência da cultura renascentista, firmada na condição de tomar o homem como sujeito no mundo e seus desdobramentos em termos da arte e da história, especialmente, quando esses novos conhecimentos decorriam de experiências vividas e únicas, não porque fossem experiências individuais, mas porque nelas continham todas as outras tradições anteriores. Disso decorria também a surpresa de notar que o Novo Mundo foi inventado antes de ser descoberto ao mesmo tempo em que essas experiências tomavam corpo e definiam conceitos e teorias sobre o homem, o mundo e a natureza na Europa.

Diante do exposto nesse primeiro parágrafo, peço que aqueles que começam a ler ensaio tenham paciência. Talvez enfrentem na leitura desconfianças e conflitos que decorrerão da forma pela qual apresento a minha hipótese. Ela parte de um conjunto de reflexões que venho fazendo ao longo dos anos e que acumularam dois dos temas que mais me envolvo. De um lado, a cultura renascentista e nela em especial as cidades renascentistas, suas formas, seus princípios e especialmente os modos de viver e de agir, ou seja, a vida ativa. De outro, a cidade do Rio de Janeiro, tema que venho explorando nos últimos anos e que, possam imaginar leitores, talvez esteja muito longe do primeiro tema indicado.

Fazia-me espécie, a exclusão quase absoluta dos elementos dessa cultura renascentista na historiografia que pretendia dar conta das explicações relativas ao povoamento e colonização do Novo Mundo. Além dessa exclusão, ficava claro também o menosprezo que ela dava ao mundo ibérico, desvinculando-o totalmente do universo de valores europeus de seu tempo e infantilizando a sua história ao definir esse mundo como ainda marcadamente feudal. Daí decorrem duas situações, entre outras, que merecem atenção: que a presença ibérica na América havia destruído uma cultura tradicional que, se mantida, acabaria por transformar a realidade atual e teria conduzido a América em direção a outro estágio do desenvolvimento; e que as formas de povoamento indicavam que as preocupações ibéricas eram, de um lado, religiosas e, de outro, mercantis, e isso 
esgotava a condição de avaliação da presença europeia e da cultura renascentista na sua passagem pela América.

O que ocorreu, entretanto, é que fui aos poucos descobrindo relações que me fizeram aventurar-me na possibilidade de reunir os dois temas, ou melhor, os dois conjuntos temáticos. Fiz isso a partir de um projeto intitulado América Renascentista: o Rio de Janeiro, uma cidade renascentista nos trópicos. No fundo, a oportunidade de juntá-los veio da minha participação num simpósio internacional sobre utopias. Quando recebi o chamado para participar a ideia de caminhar pela combinação saltou ao pensamento e abriu caminho para o que vocês lerão a seguir.

A hipótese da qual partia já estava constituída pelo próprio título do projeto: a cidade do Rio de Janeiro era uma cidade renascentista nos trópicos. O ponto de partida foi a especificidade da cidade do Rio de Janeiro ao longo da sua história e particularmente no seu momento inaugural. Para vocês compreenderem melhor do que falo lá vai história.

\section{Ponto de Partida}

A origem da hipótese que construí derivou da leitura de dois livros, para mim centrais para a concretização dos argumentos. O primeiro foi A civilização do Renascimento na Itália de Jacob Burckhardt (1988), em especial a parte referente à descoberta do homem e do mundo quando o autor me deu duas pistas.

A primeira, a ideia de que mais importante do que a descoberta era a invenção. Afirmação aparentemente pouco significativa, mostrou-se muito estimulante porque me abriu caminho para a observação da recepção da descoberta do Novo Mundo na Europa renascentista. Pude, então, olhar com mais atenção para as releituras que os homens modernos europeus fizeram dos textos romanos, em especial, de Plínio, o velho, responsável pela derivação da prioridade da invenção sobre a descoberta quando dizia ser impossível não existirem terras na parte do mundo oposta a Europa. Sua dedução partia do conhecimento que na época os romanos possuíam da África e da Ásia e desenvolvia uma suposição lógica de que se a terra girava em torno de si mesma, senão houvesse um equilíbrio entre os hemisférios, a terra giraria tão rapidamente que seria impossível medir o dia como haver vida. De tal forma, que a terra oposta era o peso necessário para o equilíbrio e para a vida.

A segunda pista de Burckhardt veio da ideia de que o renascimento prestou muita atenção a Colombo, e a curiosidade em torno dos relatos de suas viagens acabou por ser 
incorporada ao imaginário da época nas formas de criação da base para o desenvolvimento de tipos de pensamentos que originaram as noções de sonhos e de utopias, especialmente, durante o século XVI.

O segundo livro foi A invenção da América, de Edmundo O'Gorman (I992), que completou as pistas indicadas por Burckhardt, ao fazer uma "fortuna crítica" da presença da América no pensamento renascentista, abrindo caminho para que eu pudesse avançar no sentido de entender mais claramente como o Novo Mundo se tornou objeto de reflexão de várias linhas de pensamento europeias no tocante as noções de ideais e utopias. Em especial, como já havia mencionado em outro artigo, no período das guerras civis religiosas, que transformaram o Novo Mundo num paraíso de paz, de tranquilidade, ou seja, na referência maior para os sonhos renascentistas. (RODRIGUES; FALCON, 20Io).

\section{Desdobramentos}

As pistas me levaram a buscar os pontos de contato e, a partir daí, as particularidades não observadas pela historiografia: porque esta partia, todo tempo, da ideia de que a América era puro resultado do processo de desenvolvimento do mercantilismo europeu, em especial, o ibérico. Isso não permitia que pudéssemos observar as relações de troca que me levam a pensar a América como renascentista. Para esse desdobramento foi fundamental a leitura dos livros de Serge Gruzinski, em especial, La guerra de las imagens (2013) e, em particular, um pequeno texto, publicado nos Cadernos de Pós-Graduação da Unicamp, intitulado Os índios pintores renascentista da América, no qual o autor mostrava a recepção dos valores renascentistas por parte dos povos americanos.

Mas, para mim, o interesse era mais específico. Tratava-se de concentrar atenção num determinado lugar no Novo Mundo: o Brasil. E mais pontual ainda na cidade do Rio de Janeiro. Para isso, mais dois livros foram importantes: A cidade das letras, de Angel Rama (I982), e Raízes do Brasil, de Sérgio Buarque de Holanda (I936).

A importância deles decorreu da necessidade de pensar a cidade colonial, como a historiografia define. A questão, no fundo, decorreu das comparações que Sérgio Buarque de Holanda faz entre as colonizações espanhola e portuguesa, diferenciando-as da seguinte forma: na parte espanhola haveria a criação de cidades enquanto na portuguesa feitorias. Essa diferença é feita num capítulo intitulado $O$ semeador e o ladrilhador, denominações que, grosso modo, atribuem aos portugueses um sentido aproximado da noção de puros 
exploradores da terra e aos espanhóis a condição de artesãos, de pensadores, que olham para as terras e tentam ocupá-las de modo a criarem uma possível civilização.

Não é o caso aqui de entrarmos mais fundo nesse debate. Para mim, a ideia a ser desenvolvida é de que a cidade do Rio de Janeiro é uma cidade clássica, como diria Rama e não uma feitoria. E, em geral, tenho ideia que as demais cidades portuguesas na América também não foram simples feitorias. Isso não quer dizer que eles não se vincularam ao pensamento mercantilista da época, mas que exprimiam uma etapa da política portuguesa que imaginava as cidades no Novo Mundo como responsáveis diretas pela realização plena de riquezas, ou seja, elas foram importantes no processo de aumento da velocidade de circulação, central para o processo de produção de lucros.

Desse modo, os portos eram centrais, mas também as áreas de produção. A América ensinou que sem o equilíbrio entre produção e circulação a operação de riqueza ficava vulnerável a crises. Isso configurava as cidades como tendo duas portas, uma aberta para a Europa e outra para o interior, garantindo o sentido da ocupação.

Definidos esses aspectos mais gerais, importava dedicar-me ao meu tema principal: a cidade do Rio de Janeiro e suas particularidades.

\section{Particularidades}

A primeira particularidade que me fez desenvolver a hipótese foi a de ser uma cidade com uma dupla fundação. Explico. As terras que compreendem a cidade do Rio de Janeiro foram pisadas por duas diferentes culturas renascentistas: francesa e portuguesa. De modos diversos, essas duas culturas se combinaram com a cultura indígena que ocupava as terras que formaram espaço urbano do Rio de Janeiro.

A segunda particularidade nos remete ao modo de realização dessa combinação: guerra e violência. Uma guerra de símbolos cujo maior troféu foi demarcar o território com o sangue de franceses, portugueses e índios.

A terceira particularidade está estabelecida pelos principais personagens da guerra: Mem de Sá e Nicolau Durand de Villegnon. Ambos homens que experimentaram a Renascença e que tiveram a sua disposição os textos que Américo Vespúcio escreveu sobre a Baía da Guanabara, a produção de Colombo, e as reflexões de Thomas Morus. Esse conjunto de textos, direta ou indiretamente, provocou em ambos, por conta de suas formações, uma visão de mundo sobre a América que deu origem a sua vinda para o Brasil. 
No caso do francês acrescente-se a amizade com André Thevet e a leitura do seu livro Singularidades da França Antártica. Além disso, Nicolau formou-se em teologia na Universidade de Paris e no período em que lá esteve conheceu Calvino, o futuro reformador protestante. Com ele conviveu, realizando debates sobre teologia e sobre o que acontecia com a igreja na Europa. Se associarmos as leituras sobre o Novo Mundo com o clima de tensão na Europa, derivado das guerras religiosas é possível compreender, com a leitura de suas cartas, que sua trajetória intelectual pode ter o levado a construir um projeto de cidade no Novo Mundo.

Quanto a Mem de Sá, sabemos que vivia na corte e se esmerou em conhecer o pensamento de sua época, lendo os textos produzidos na Itália e na Holanda, tendo como apoio no entendimento do que lia seu irmão, Sá de Miranda, junto com Camões, um grande poeta da renascença portuguesa. A ambiência intelectual na corte portuguesa era uma das mais importantes da Europa, não apenas na náutica ou na geografia, mas na filosofia com grande influência da combinação Platão/Aristóteles e na formação de uma sabedoria sobre o mar. Esse conjunto associado à leitura de suas cartas mostra, também no caso do português, a possibilidade de imaginar que passavam por sua cabeça ideias e sonhos renascentistas.

A reunião do português e do francês marca a possibilidade de presença das experimentações renascentistas no Novo Mundo, em especial, na cidade do Rio de Janeiro.

A quarta particularidade decorreu do lugar ocupado pela cidade do Rio de Janeiro no cenário geral da colonização portuguesa. Diferente de Salvador, capital da colônia, o Rio de janeiro ficava geograficamente mais ao sul. Essa posição fazia da cidade um lugar especial para as rotas de navegação que se dirigiam das Índias para a Europa e para os navegadores espanhóis que saiam da área do Prata em direção à Espanha, tentando se livrar da presença de piratas e corsários. Mas, pensemos mais fundo no lugar da cidade no mundo do mercantilismo.

Sabemos que a política mercantil estava fortemente associada ao Estado, fazendo com que, no caso português, os monopólios e privilégios dados aos comerciantes fossem a base da economia do Estado português. Daí o estabelecimento de controles para que não houvesse perda de lucros. Essa condição da política mercantil associada às condições naturais da Baía da Guanabara fez do porto da cidade o lugar mais importante do Atlântico Sul. Com isso, trafegavam por aqui as culturas mais variadas e que davam à cidade um perfil cosmopolita, ou seja, de uma cidade aberta para o mundo. Além disso, pelo distanciamento geográfico de Salvador, o Rio se tornava o paraíso dos ganhos por fora do 
controle do sistema português, sendo comercializados produtos sem os custos dos tributos da aduana.

Um dos indícios claros disso é a presença de comerciantes do Rio de Janeiro em Buenos Aires antes do final do século XVI, como atesta o livro de Alice Canabrava (I982). Entretanto, além da presença mercantil, eles foram mais longe e criaram colônias, dentre as quais a mais importante foi a Colônia do Sacramento, em pleno rio da Prata; atestando a capacidade de ação daqueles que constituem a população fundadora.

A última particularidade diz respeito ao modo de governar e de agir na cidade. A marca que decorre desse conjunto de particularidades é a constituição de uma cidade de colonos e não colonizadores e nem de colonizados. O que significa que os habitantes do Rio de Janeiro se envolveram com o chão, de tal forma, que o transformaram num espaço de construção de formas de sociabilidade que refletem, de forma genérica, as marcas das cidades renascentistas (sobretudo no sentido das virtudes que orientam a ordenação do espaço e a sua qualificação como cidade).

As ações descritas pelos anais da Câmara Municipal anunciam modos muito próximos aos que eram desenvolvidos nas Repúblicas renascentistas, principalmente com relação à valorização das relações entre os habitantes e sua devoção à cidade. Arrisco dizer que há algo muito próximo entre a noção de virtu cívica das repúblicas italianas cívica e as atitudes que decorrem dos debates na Câmara.

Sintetizando o que até agora foi apresentado, a recepção dos valores do Renascimento no Novo Mundo, em especial, na cidade do Rio de Janeiro, combina a produção da Renascença, em especial, a ideia de utopia e, com a ideia de República na maneira pela qual o Rio de Janeiro se torna o campo privilegiado de combinação de ideias e experiências.

\section{Aclaramentos}

Foi justamente essa tese que me levou a pesquisar a cidade do Rio de Janeiro, procurando elementos em seu processo de construção que refutassem a tese de feitoria e aproximassem a cidade da cultura renascentista através de uma das polêmicas mais interessantes do Renascimento: que é aquela que permite associar Alberti e Thomas Morus na relação cidade ideal/cidade utópica. 
Essas considerações, alicerçadas nas ideias mais gerais acima apresentadas, adquirem sentido quando em sua referência ao espaço e lugar da cidade do Rio de Janeiro permitem considerar:

a. As formas de atuação europeia na América, mesmo marcadas por processo de acentuada repressão, representam a afirmação da cultura renascentista na sua versão ibérica, daí decorrendo que a América se torna um espaço de experimentação da explosão criativa da cultura do século XVI.

b. A América como campo de experimentação estabelece a ideia de um espaço de complementariedade entre cultura europeia e natureza do Novo Mundo, que tem como resultado a inserção na América em dois modos distintos de interpretação do Novo Mundo: um que o pensa como espaço de crítica e acentua seu sentido alegórico como reconstrução de um novo conceito de civilização que se desdobra, por sua vez, em duas tendências, aquela que vê o Novo Mundo como volta ao Paraíso ou ao Jardim das Delícias; e a outra que a toma como lugar do futuro, onde se afirma a potência do homem em transformar a natureza.

c. A cidade do Rio de Janeiro pode ser tomada como um espaço peculiar de ação desses dois modos que acabam por criar uma situação de reciprocidade, e dão à cidade uma inserção particular no contexto do sistema colonial português no Novo Mundo.

d. A cidade do Rio de Janeiro será considerada como o lugar singular de constituição de uma sociedade de colonos que projetam sobre o Rio de Janeiro uma forma urbana que atua paralelamente ao sistema de controle do Estado português, produzindo inclusive um processo de acumulação de riquezas por fora do sistema colonial, fazendo a cidade dispor de um grau de autonomia e liberdade distinto da capital da região colonial - Salvador.

e. Ao contrário de Salvador, o Rio de Janeiro é uma cidade aberta para o mundo e, por isso, apresenta-se como receptora das polêmicas do renascimento.

Nesse mesmo plano, vale ainda lembrar a necessidade de recolocar a questão da dupla fundação da cidade do Rio de Janeiro, no sentido da presença portuguesa e francesa. Como esta temática é muito vasta e extrapola os limites deste artigo, centrarei a minha análise na observação da cidade do Rio de Janeiro como espaço de ação de projetos utópicos.

O exemplo das cidades utópicas é sem dúvida a Ilha da Utopia de Morus. Todo o Livro II, onde se descreve o lugar físico e social da Utopia, é acentuadamente espacial, e os princípios morais e éticos decorrem, em seu aspecto de força, do modo de inserção no espaço. No caso de Alberti, há dificuldades de encontrar autores que compartilhem a ideia 
de que sua produção, de uma amplitude temática imensa, vá além do que especificamente observações pontuais sobre pintura e arquitetura e que, nesse conjunto de reflexões, a construção das cidades ideais apareça fragmentada. A hipótese é que, distinto de Morus, onde a cidade utópica toma forma na Ilha da Utopia, Alberti, pelo seu alto grau de intervenção no cotidiano, apresenta a construção da cidade ideal de forma assistemática.

Entretanto, basta ler com atenção as suas reflexões para se sentir tomado por uma sensação estranha de que a cada passo da leitura, não só o mundo renascentista com todas as suas nuanças ganha forma, mas as situações adquirem a qualidade da construtibilidade e da espacialidade. Para manter essa leitura interpretativa de Alberti é preciso ultrapassar as visões que dele se construíram, principalmente, a de Giorgio Vassari que o reduz a mero organizador de métodos dos outros. Muitos procuram a sua cidade ideal em desenhos ou projetos, outros em cidades reais que mereceram de Alberti algum tipo de intervenção. Poucos, entretanto, procuram a sua cidade ideal costurando por dentro os seus textos.

No caso de Alberti, é fundamental que se trabalhe com o plural - cidades ideais pois seu discernimento do mundo e sua perspicácia quanto às relações entre homem e espaço obriga-nos a pensar na multiplicidade de arranjos distintos com relação à cidade. Se a leitura de De re aedificatoria procurar algo mais do que leis para a construção, identificarse-ão propostas e princípios das cidades ideais e críticas às cidades reais.

A cidade ideal de Alberti está num pequeno comentário que estabelece, por exemplo, a aproximação entre a casa e a cidade; a cidade ideal é igual à casa ideal, o que determina a localização dos critérios de harmonia, beleza, conforto e equilíbrio como prérequisitos para as cidades ideais. A arquitetura e a pintura são tomadas pelo humanista como chaves para demonstrar a potência do homem em ultrapassar a natureza sem deixar de imitá-la na sua configuração matemática, elaborando, a partir daí, a teoria das proporções.

Da mesma forma, para entender Morus é preciso ultrapassar os lugares comuns de interpretações absolutas e procurar os motivos e os princípios das cidades utópicas em Erasmo, Damião de Góes, no movimento da Devotio Moderna, nos relatos dos descobrimentos portugueses e espanhóis, e nos debates intelectuais, políticos e diplomáticos da Holanda. Não para reduzir suas reflexões a meras descrições daquilo que ouviam, mas para mostrar a força da inventiva individual e o espírito aberto de Morus.

O conhecimento do Novo Mundo acarreta o desenvolvimento da crítica social e desempenha papel importante na produção das cidades ideais e utópicas. Entretanto, a 
força dessas respostas críticas é maior porque o Novo Mundo foi dado a conhecer e gerou um processo de rediscussão do significado da civilização e da ideia de Europa.

Os relatos das Índias indicam, por vezes, assombro e, por outras, superioridade e desprezo, mas qualquer que seja a atitude, o resultado anuncia contrastes. É essa condição do texto-relato que o faz surgir como intermediário, como um lugar nenhum, e que é diferente em Montaigne e em Córtez. A circulação das informações e as comparações que elas permitem levam tanto à produção do conceito de "guerra justa" como ao conceito de "bom selvagem", sem que Montaigne ou as autoridades papais tenham estado no Novo Mundo.

Mas além desses conceitos de ordem moral ou econômica, também surgem apreciações que associam modos e costumes ao lugar natural. Algumas relacionando-as através do mito de uma volta da fabulosa "Idade de Ouro"; outras ao projeto de uma troca capaz de fazer a Europa superar suas crises.

Essa segunda forma de relacionar a apreciação é que culmina na produção das cidades ideais e das cidades utópicas, possibilitando uma diferenciação entre elas. As cidades ideais vinculam-se a um projeto de reformas das cidades reais. Seu espaço construtivo não é equidistante da cidade real. A cidade ideal convive com a cidade real e funciona como alarme em situações de crise. Essa noção decorre do primeiro humanismo renascentista, anterior ao realismo de Maquiavel, no qual Alberti tem uma presença significativa e que diante das crises opta pela capacidade vigorosa do homem renascentista de superar os seus limites.

Dessa forma, as cidades ideais são imaginadas a partir da dinâmica interna das cidades reais, não necessitando de um elemento externo para adquirir sentido e ganharem forma. Por isso, sua representação imagética tende a associá-las à cultura aristocrática, ao refinamento nobre e à arte no sentido de sua força estética. Entretanto, são essas cidades ideais que se afirmam como modelos para a construção das cidades coloniais na América Ibérica. Os critérios de ordem das cidades ideais têm uma dinâmica assegurada pela geometrização de sua imagem, que é, ao mesmo tempo, o limite de sua característica ideal e também sua fronteira.

As cidades utópicas, ao contrário, constituem-se a partir de um espelho externo para depois voltarem-se para dentro das cidades reais, precisam de um espaço constituído como "alhures" ou "lugar nenhum" para existirem.

Por isso, são mais difíceis de serem construídas no imaginário e possuem um ordenamento físico muito mais detalhado. Como já são produções da segunda fase do 
humanismo, posterior a Maquiavel, as cidades utópicas expressam valores éticos e morais associados ao lugar geográfico; quase todas tendo como elemento comum estarem separadas do mundo real pelo braço de mar ou por um rio, adquirindo a feição de uma "ilha" isolada.

O detalhamento dos costumes, hábitos e instituições é a forma de projetar radicalmente suas críticas ao mundo real, diferenciando-se das cidades ideais, nas quais a estética da cidade gera um prazer capaz de alterar hábitos e produzir novas relações de sociabilidade. Nas cidades utópicas a ideia de produção se mantém presente como ponto de equilíbrio entre os habitantes, já que a propriedade privada foi abolida.

Nas cidades utópicas há um aparente cancelamento do "eu" e os ideais de liberdade e autonomia são regulados pelos preceitos morais contidos em cada um daqueles que habitam as cidades utópicas. Nas cidades ideais mantém-se o "eu" renovado e a noção de sujeito adquire o sentido de criador e planejador. Entretanto, uma leitura atenta das cidades utópicas mostra que o cancelamento do "eu" é um processo de intervenção ativa do sujeito, que ao ser capaz de perceber o desastre, como fim do caminho de grandeza do homem renascentista, propõe uma cura diferente daquela que está presente nas cidades ideais.

Essa cura projetada como cancelamento e/ou intervenção aproxima Morus e Maquiavel. Também, para o florentino, trata-se de superar o desastre que se aproxima e também a cura verifica-se pela produção de uma imagem de intervenção que, no caso de Maquiavel, é a de um "príncipe", que metaforicamente é a imagem do homem em sua tentativa desesperada de superar o desastre. No caso de Morus é a Ilha da Utopia que se afirma como metáfora da nova cidade/nova humanidade.

A cidade do Rio de Janeiro marcou o seu território com uma dupla presença de tendências utópicas. De um lado, o projeto da França Antártica, articulado por muitas mãos, e que teve um comandante francês, erudito da Renascença e temeroso com as reformas religiosas, como realizador - Villegagnon. De outro, o sonho de um visionário como Mem de Sá, irmão de Sá de Miranda. A guerra que se estabeleceu na terra carioca resultou na constituição de uma cidade de colonos, ideal e utópica.

\section{Referências Bibliográficas}

ALBERTI, Leone Battista. Da pintura. São Paulo: Edunicamp, 1992. 
ALBERTI, Leone Battista. On the art of building in tem books. Cambridge, Mass.: MIT Press, 1988.

ARGAN, Giulio Carlo. História da Arte como História da Cidade. São Paulo: Martins Fontes, I99I.

BURKHARDT, Jacob. A cultura do Renascimento na Itália. São Paulo: Cia das Letras, 1988.

CANABRAVA, Alice P.. O comércio português no Rio da Prata. São Paulo/Belo Horizonte: Edusp/Itatiaia, 1982.

CHOAY, Françoise. A Regra e o Modelo. São Paulo: Perspectiva, 1986.

DUBOIS, Claude-Gilbert. O imaginário da Renascença. Brasília: Eunb, 1995.

ELLIOT, J. H. O velho mundo e o novo. I492-I650. Lisboa: Editorial Querco, 1987.

GRUZINSKI, Serge. La guerra de las imagenes. México: FCE, 2013.

HOLANDA, Sergio Buarque de. Raízes do Brasil. Rio de Janeiro: José Olympio, 1936.

MORUS, Thomas. A utopia. São Paulo: Martins Fontes, 2006.

O’GORMAN, Edmundo. A invenção da América. São Paulo: Editora da Unesp, 1992.

RABELAIS, François. Gargantua. São Paulo: Hucitec, 1982.

RAMA, Angel. A cidade das Letras. São Paulo: Brasiliense, 1982.

RODRIGUES, Antonio Edmilson M.; FALCON, Francisco. A formação do mundo moderno. Rio de Janeiro: Ed. Campus/Elsevier, 20ı.

RODRIGUES, Antonio Edmilson M.; FALCON, Francisco. Tempos modernos. Um ensaio de história cultural. Rio de Janeiro: Civilização Brasileira, 2000.

SKINNER, Quentin. Los Fundamentos del Pensamiento Politico Moderno. I. El Renacimiento. México: FCE, 1985. 